\title{
EFFECT OF PRIMYCIN ON MONOVALENT CATION TRANSPORT OF ERYTHROCYTE MEMBRANE AND LIPID BILAYER
}

\author{
Katalin Blaskó, Sándor Györgyi and István Horváth* \\ Institute of Biophysics, Semmelweis University Medical \\ School, 1088 Budapest, Hungary \\ *Second Institute of Biochemistry, Semmelweis University \\ Medical School, 1088 Budapest, Hungary \\ (Received for publication January 4, 1979)
}

\begin{abstract}
The effects of primycin were investigated on the alkali-cation transport of human erythrocytes and on the electric conduction of bimolecular lipid membranes. In the concentration range of $3 \cdot 10^{-6} \sim 10^{-5} \mathrm{M}$ primycin increased the permeability of erythrocytes to alkali-cations according to the sequence $\mathrm{Cs}^{+}>\mathrm{Rb}^{+} \sim \mathrm{K}^{+} \gg \mathrm{Na}^{+}$, while the conductance of the negatively charged phosphatidylserine bimolecular lipid membrane increased by $2 \sim 3$ orders of magnitude. The resistance-lowering effect of primycin strongly depended on the cationic species applied and a selectivity order $\mathrm{Na}^{+}>\mathrm{K}^{+}>\mathrm{Rb}^{+}>\mathrm{Cs}^{+}$was found. A possible mechanism of the primycin-membrane interaction is suggested on the basis of experimental data.
\end{abstract}

The antibiotic primycin was first isolated by VÁLYI-NAGY et al. in $1954^{1)}$ and its chemical structure was established by ABerhart et $a l^{2}{ }^{2}$ and FeHr et $a l^{3)}$ Primycin has an activity against Grampositive pathogens, human and bovine Mycobacterium tuberculosis. Starting from BLum's experiments ${ }^{4}$ V áLYI-NAGY et al. came to the conclusion that primycin might act as an inhibitor of the DNA-dependent RNA synthesis ${ }^{5)}$. Horváth et al. ${ }^{6)}$ have recently shown that primycin selectively increases the permeability of Gram-positive bacteria and this effect was suggested as responsible for its bacteriostatic action. A primycin-membrane interaction has received support also from experiments on rat liver mitochondria by Mésż́ros et al. ${ }^{7)}$ The authors have concluded that primycin, up to a concentration of $2 \sim 3$ nmoles/mg protein, acts as an ionophore for certain monovalent cations in mitochondria while above this concentration the inner membrane becomes permeable also to protons and smaller anions. In order to have a better insight into this ionophore-like action of primycin, its effects were studied on the alkali cation transport of human erythrocytes and on the electric conductance of bimolecular lipid membranes being widely used to monitor such problems ${ }^{8 \sim 13)}$. It is demonstrated that primycin selectively increases the alkali-cation permeability of erythrocyte membranes and drastically decreases the electric resistance of the negatively charged phosphatidylserine bimolecular lipid membrane.

\section{Materials and Methods}

\section{Chem icals}

Primycin, gift of Chinoin Pharmaceutical Works (Budapest, Hungary), was dissolved in dimethylsulfoxide (DMSO) in a concentration of $10^{-3} \mathrm{M}$. Aliquots of this stock solution were used in the experiments so that the final concentration of DMSO never exceeded $1 \%$ by volume. In separate experiments it was found that such concentrations of DMSO exerted no significant effects either on the

* To whom correspondence should be sent. 
alkali ion transport of erythrocytes or on the conductance of bimolecular lipid membranes. Bovine phosphatidylserine was supplied by Koch-Light (Colnbrook Bucks, England) and used without further purification. Chloride salts of alkali cations were of analytical grade.

Determination of alkali-cation efflux

Freshly drawn, heparinized blood from healthy volunteers was equilibrated with the radioactive isotopes of ions to be measured $\left(e . g .{ }^{22} \mathrm{Na},{ }^{42} \mathrm{~K},{ }^{86} \mathrm{Rb},{ }^{137} \mathrm{Cs}\right)$ at $37^{\circ} \mathrm{C}$ for 1.5 hours. Then the blood was centrifuged, the plasma and buffy coat were removed, and the erythrocytes were washed 3 times with cold LOCKE solution and finally resuspended into the same solution to give a final haematocrit of about $40 \%$. This procedure was carried out to avoid any possible interaction of primycin with plasma proteins. Appropriate amounts of the primycin stock solution were added to the suspension to achieve a plasma concentration of $3 \cdot 10^{-6}$ or $10^{-5} \mathrm{M}$ and then the suspension was incubated at $20^{\circ} \mathrm{C}$ in the case of ${ }^{42} \mathrm{~K},{ }^{86} \mathrm{Rb}$ and ${ }^{187} \mathrm{Cs}$, or at $37^{\circ} \mathrm{C}$ for ${ }^{22} \mathrm{Na}$ while carefully stirred. Sampling was made in 30-minute intervals and the activity of the extracellular solution was measured with a scintillation counter. The cation permeability of erythrocyte membranes were characterized by the amount of radioactive ions released under given periods of time.

Determination of alkali cation influx

A suspension of washed red blood cells was warmed up to $37^{\circ} \mathrm{C}$ and kept at this temperature for 1 hour. Then primycin and the radioactive ions were added and the suspension was further incubated at $37^{\circ} \mathrm{C}$ (with ${ }^{42} \mathrm{~K},{ }^{86} \mathrm{Rb},{ }^{137} \mathrm{Cs}$ ) or at $20^{\circ} \mathrm{C}$ (with ${ }^{22} \mathrm{Na}$ ). During incubation samples were taken in 30-minute intervals and the activities of the extracellular solution measured. The influx was characterized by the decrease of the specific activity of the extracellular compartment during the time of incubation and was expressed as the percent of initial specific activity.

Influx and efflux measurements were made in five independent runs, numerical values given are the averages of five independent determinations.

\section{Electric measurements}

Electric measurements were carried out on bimolecular lipid membranes (BLMs). BLMs separating $10^{-3} \mathrm{M}$ chloride solutions of monovalent cations with identical concentrations were made from $2 \%$ decane solutions of bovine brain L-phosphatidylserine on a $1.5-\mathrm{mm}$ diameter hole of a Teflon cup. The solutions were adjusted to $\mathrm{pH} 4$ using diluted $\mathrm{HCl}$ solution. Two identical calomel electrodes (OP 815, Radelkis, Hungary) were immersed into the bathing solutions, and the electric circuit was completed through a potential box and a Keithley electrometer amplifier ${ }^{14)}$. Primycin was added to the aqueous salt solution either on one or on both sides of the membrane after the BLM formation, and the current was measured as the function of the external voltages or time. All measurements were carried out at $25 \pm$ $0.1^{\circ} \mathrm{C}$.

\section{Results}

Extracellular primycin increased the cation permeability of the erythrocyte membrane as seen in Fig. 1, where typical efflux values of $\mathrm{K}^{+}, \mathrm{Rb}^{+}$and $\mathrm{Cs}^{+}$ions and influx values of $\mathrm{Na}^{+}$ion are plotted against incubation time at $3 \cdot 10^{-6} \mathrm{M}$ and $10^{-5} \mathrm{M}$ primycin concentrations, respectively. The
Fig. 1. Time dependence of $\mathrm{K}^{+}, \mathrm{Rb}^{+}$and $\mathrm{Cs}^{+}$effluxes and $\mathrm{Na}^{+}$influx at different primycin concentrations $\left(3 \cdot 10^{-6}\right.$ and $10^{-5} \mathrm{M} /$ liter plasma). Temperature of incubation was $20^{\circ} \mathrm{C}$.

Ordinate gives the amount of radioactive ions transported expressed in the percent of total activity.
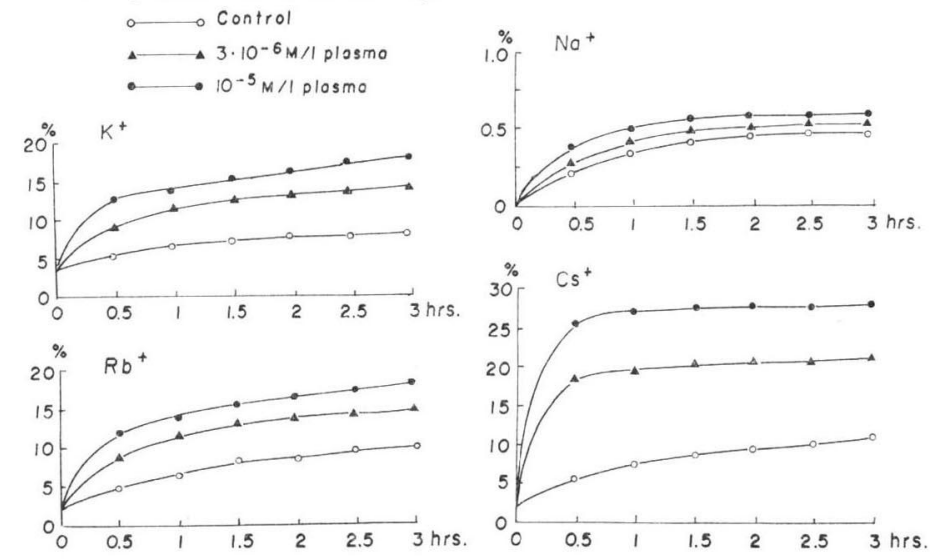
most pronounced effect of primycin was found on the $\mathrm{Cs}^{+}$efflux. Half an hour after adding $3 \cdot 10^{-6} \mathrm{M}$ primycin the amount of $\mathrm{Cs}^{+}$effluxed was about three times higher, while that in the presence of $10^{-5} \mathrm{M}$ primycin was five times higher as compared to the control. The $\mathrm{K}^{+}$ and $\mathrm{Rb}^{+}$effluxes increased in the same manner also, when primycin was present, but to a lesser extent in comparison to that of $\mathrm{Cs}^{+}$. Primycin had no significant effect on passive $\mathrm{Na}^{+}$influx.
Table 1. Effect of primycin on passive ion fluxes of erythrocytes.

\begin{tabular}{c|c|c|c|c}
\hline $\begin{array}{c}\text { Extracel- } \\
\text { lular } \\
\text { antibiotic } \\
\text { conc. }\end{array}$ & $\begin{array}{c}\mathrm{Na}^{+} \\
\text {(influx) }\end{array}$ & $\begin{array}{c}\mathrm{K}^{+} \\
\text {(efflux) }\end{array}$ & $\begin{array}{c}\mathrm{Rb}^{+} \\
\text {(efflux) }\end{array}$ & $\begin{array}{c}\mathrm{Cs}^{+} \\
\text {(efflux) }\end{array}$ \\
\hline $3 \cdot 10^{-6} \mathrm{M}$ & $112 \pm 10$ & $183 \pm 15$ & $169 \pm 15$ & $252 \pm 15$ \\
$1 \cdot 10^{-5} \mathrm{M}$ & $137 \pm 12$ & $238 \pm 20$ & $215 \pm 20$ & $360 \pm 12$ \\
\hline
\end{tabular}

The transport rate values are expressed in percentages of the appropriate controls taken as $100 \%$ calculated from the results obtained after an incubation time of one hour.

For quantitative comparison the relative effects of primycin on passive ion fluxes are given in Table 1.

At most, $5 \%$ inhibition was found for the influxes of $\mathrm{K}^{+}, \mathrm{Rb}^{+}$and $\mathrm{Cs}^{+}$ions and the efflux of $\mathrm{Na}^{+}$ ion, respectively.

\section{Effect of primycin on BLM conductance}

The ohmic resistance of the negatively charged phosphatidylserine BLM bathed in $10^{-3} \mathrm{M}$ alkali chloride solution is as high as about $10^{-8} \mathrm{ohm}^{2} \mathrm{~cm}^{215}$. Significant differences of resistance when different alkali chlorides were present in the aqueous phase could not be measured. Primycin below a concentration of $10^{-6} \mathrm{M}$ did not alter the BLM resistance while above this concentration the resistance decreased depending on primycin concentration. Recording the current at $40 \mathrm{mV}$ ex:ernal voltage, it gradually increased with time and reached its saturation value in about 30 minutes. Fig. 2 shows such traces obtained with $10^{-5} \mathrm{M}$ primycin and different alkali chlorides. The highest saturation value of current was experienced for $\mathrm{NaCl}$ and the lowest one for $\mathrm{CsCl}$. The time course of these curves did not depend on the sign of voltage. Practically the same curves were recorded when primycin was present only in one or both compartments. After reaching a steady state the BLMs exhibited high mechanical stability and dielectric strength. While the lifetime of an unmodified BLM was usually $1 \sim 2$ hours, those of the modified cnes were $20 \sim 24$ hours. Fig. 3 shows the current-voltage characteristics of a BLM in the absence and in the presence of $10^{-5} \mathrm{M}$ primycin. Primycin did not alter qualitatively the shape of the curves. The steady resistance strongly depended not only on the ion species but on the primycin concentration in the bath-

Fig. 2. Time dependence of electric current through BLM in the presence of $10^{-5} \mathrm{M}$ primycin.

BLM was made of phosphatidylserine in $10^{-3} \mathrm{M}$ chloride solutions of different monovalent cations, pH 4.1.

Current was measured at $40 \mathrm{mV}$ external voltage at $25^{\circ} \mathrm{C}$.

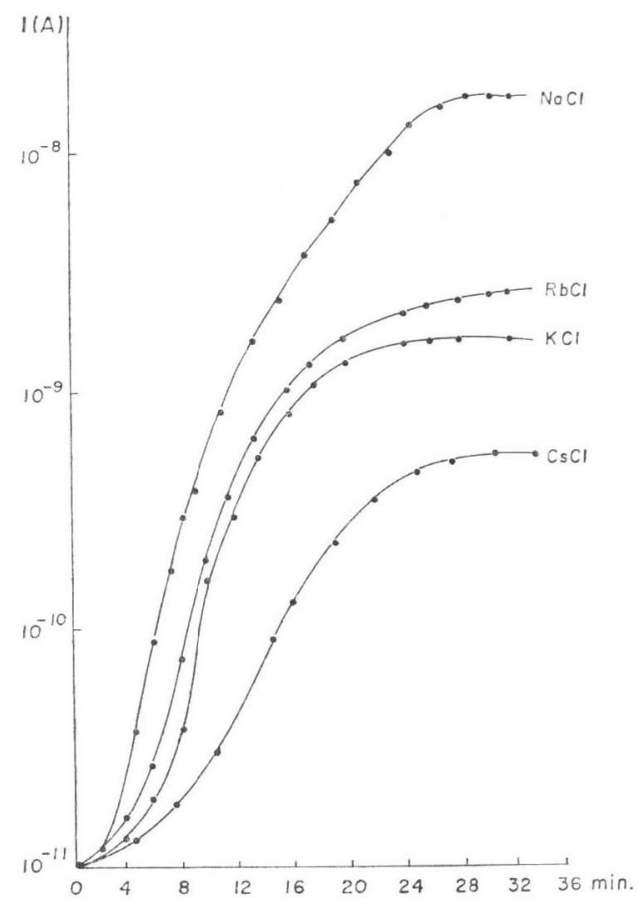


Fig. 3. The current-voltage characteristics of BLM without (a) and with (b) primycin, BLM was made of phosphatidylserine in $10^{-3} \mathrm{M} \mathrm{NaCl}, \mathrm{pH} 4.1, \mathrm{t}=25^{\circ} \mathrm{C}$.

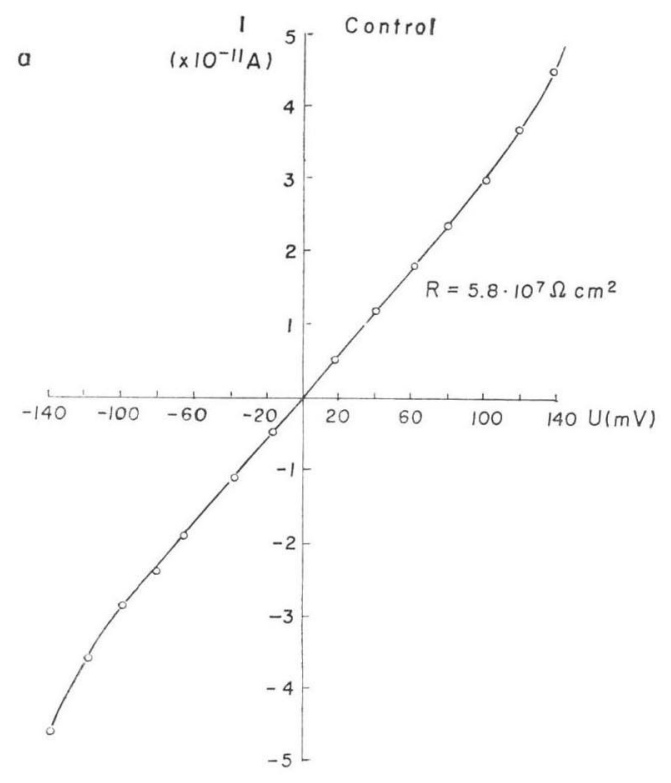

ing solution. Fig. 4 presents the current-voltage characteristics of a BLM at different primycin concentrations in the low voltage region. A rise of the primycin concentration from $10^{-6} \mathrm{M}$ to $10^{-5} \mathrm{M}$ yielded a drop of the BLM resistance by two orders of magnitude.

\section{Discussion}

These studies clearly demonstrate that primycin behaves like an ionophore not only in mitochondria ${ }^{7)}$ but also in the erythrocyte membrane and lipid bilayers.

Human erythrocytes selectively transport monovalent cations against concentration gradient with a sequence of $\mathrm{Rb}^{+}>\mathrm{K}^{+}>\mathrm{Cs}^{+16}$ ), but in the passive effluxes of these cations no considerable differences were found ${ }^{17)}$. On adding primycin to the erythrocyte suspension the passive permeability of the membrane increased in a selective manner. The observed selectivity sequence is: $\mathrm{Cs}^{+}>\mathrm{K}^{+} \sim \mathrm{Rb}^{+} \gg \mathrm{Na}^{+}$, which does not coincide with the selectivity orders observed either in the active or in the passive cation transport. This finding indicates that primycin may affect both transport pathways.

This ionophore-like effect of primycin can be compared to that of lienomycin which has a very similar molecular structure, but not the same effect on mitochondria and erythrocytes ${ }^{18,19)}$. Both molecules have a large lactone ring, a sugar and a basic group. However, primycin does not contain a polyenic chromophore and its guanidino group is a stronger base than the amino group of lien-
Fig. 4. Ohmic parts of current-voltage characteristics of BLM at different primycin concentrations.

BLM was made of phosphatidylserine in $10^{-3} \mathrm{M}$ $\mathrm{KCl}, \mathrm{t}=25^{\circ} \mathrm{C}$.

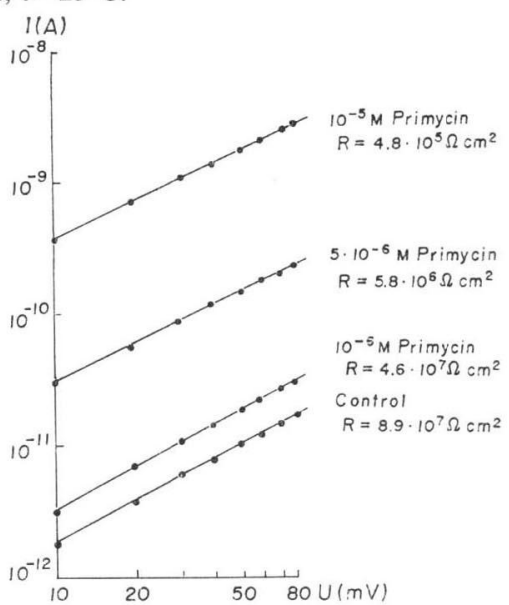


omycin. This latter difference may be one of the reasons for the differences in their actions. It seems likely that the electrostatic interaction between the positively charged guanidino group of primycin and the negative surface charges of the membrane $e^{20,21}$ facilitates the penetration of the molecule into the membrane interior rendering the membrane permeable to the monovalent cations studied.

The results obtained on model membranes suggest that the interaction of primycin with lipid molecules has also a very important role in its ionophore-like behaviour. The characteristic time curve of the increase in conductance and the extreme stability of membrane elicited by primycin make it probable that the antibiotic molecules penetrate into the region of hydrocarbon chains of lipids. On the other hand it can be seen from Fig. 4 that the ohmic resistance of modified BLM is proportional to the second power of antibiotic concentration which suggests that two primycin molecules are needed for the transport of cations. Thus, it seems unlikely that primycin is a simple carrier for cations but a dimer of primycins opens a new transport pathway for cations in the lipid matrix, whose nature requires further elucidation.

It should be pointed out that primycin similarly to lienomycin ${ }^{18)}$ and the polyene macrolide, filipin ${ }^{22}$ but in contrast to the other polyenes ${ }^{23,24)}$, also increases the cation permeability of sterol-free membranes. It could be expected that the phospholipid constituents of the membrane are critical in their interaction with primycin.

The ion selectivity sequence observed on BLM differs markedly from that of erythrocytes. For this discrepancy both the different lipid composition and the presence of proteins in the erythrocyte membranes might be responsible.

\section{Acknowledgements}

This work was supported in part by the Chinoin Pharmaceutical Works, Budapest. We are indebted to Dr. B. KARVALY for the critical review of the manuscript. The authors are grateful to ANNA BOGDÁNYI, JUdit Fodor, ÁGNes IszLaI for their excellent technical assistance.

\section{References}

1) Vályi-Nagy, T.; J. Uri \& I. Szilágyi: Primycin, a new antibiotic. Nature 174: 1105 1106, 1954

2) Aberhart, J.; R. C. Jain, T. Fehr, P. de Mayo \& I. Szilágyi: The constitution of primycin. I. Characterization, functional groups, and degradation to the secoprimycins. J. Chem. Soc. (Perkin Trans. I) 1974: $816 \sim 826,1974$

3) Aberhart, J.; T. Fehr, R. C. Jain, P. de Mayo, O. Motl, L. Baczynskij, D. E. F. Gracey, D. B. Maclean \& I. Szilágyi: Primycin. J. Am. Chem. Soc. 92: 5816 5817, 1970

4) Blum, J. J.: Inhibition of growth of Euglena and Astasia by primycin and prevention of the effect by polynucleotides. Arch. Biochem. Biophys. 111: 353 361, 1965

5) VÁlyl-Nagy, T. \& A. Daróczy: Effects of primycin on the induction of tryptophan pyrrolase. Biochem. Pharm. 16: 1051 1057, 1967

6) Horváth, I.; M. Kramer, P. J. Bauer \& K. G. Büki: The mode of action of primycin. Arch. Microbiol. (under publication)

7) Mészáros, L.; T. König, M. Paróczay, K. NÁhm \& I. Horváth: Effect of primycin on the permeability of mitochondrial inner membrane. J. Antibiotics 32: $161 \sim 166,1979$

8) Andreoli, T. E.; P. Cook \& D. C. Tosteson: Valinomycin-a molecular sieve for cations? Abstr. Biophys. Soc. 11th Ann. Meet., Houston, Texas, 9. 1967

9) Tosteson, D. C.; P. Cook, T. E. Andreoli \& H. Tieffenber: The effect of valinomycin on potassium and sodium permeability of HK and LK sheep red cells. J. Gen. Physiol. 50: 2513 2517, 1967

10) Harfis, R. J. \& B. C. Pressman: Obligate cation exchange in red cells. Nature 216: 918 920, 1967

11) $\mathrm{BACH}$, D.: Interaction of bilayers with basic polypeptides. II. Interaction of phospholipid bilayers with copolymer L-lysine/L-phenylalanine. J. Membrane Biol. 14: 57 62, 1973

12) Hartman, W.; H-J. Galla \& E. Sackman: Polymyxin binding to charged lipid membranes. An example of cooperative lipid-protein interaction. Biochim. Biophys. Acta 510: 124 139, 1978

13) Myers, V. B. \& D. A. Haydon: Ion transfer across lipid membranes in the presence of gramicidin A. II. The ion selectivity. Biochim. Biophys. Acta 274: 313 322, 1972

14) Mueller, P.; D. O. Rudin, H. T. Tien \& W. C. Wescott: Formation and properties of bimolecular 
lipid membranes. in Recent Progress in Surface Science, Vol. 1. pp. 379 393. Academic Press, Inc., New York, 1964

15) Papahadjopoulos, D. \& S. OhKi: Stability of asymmetric phospholipid membranes. Science 164: $1075 \sim 1077,1964$

16) Györgyi, S. \& K. Blaskó: Examination of the competitive effect of alkali ions in the $\mathrm{K}^{+}, \mathrm{Rb}^{+}$and $\mathrm{Cs}^{+}$ transport of rat erythrocytes. Acta Biochim. et Biophys. Acad. Sci. Hung. 9: 97 105, 1974

17) GYÖRGYI, S. \& B. KANYÁR: Application of a three compartment tracerkinetic model for comparing the $\mathrm{K}^{+}, \mathrm{Rb}^{+}$and $\mathrm{Cs}^{+}$transport of erythrocytes. Acta Biochim. et Biophys. Acad. Sci. Hung. 7: 359 363, 1972

18) Zieniawa, T.; J. Popinigis, M. Wozniak, B. Cybulska \& E. Borowski: Ionophore-like action of lienomycin on energized membrane of rat-liver mitochondria. FEBS Letters 76: 81 85, 1977

19) Cybulska, B.; T. Zieniawa \& E. Borowski: Polyene macrolide antibiotics and specific membrane permeability changes. 12th FEBS Meet., Abstr. No. 3232, 1978

20) ZwaAl, R.F.A. \& L. L. M. VAN DeEnEN: Protein patterns of red cell membranes from different mammalian species. Biochim. Biophys. Acta 163: 44 49, 1968

21) Verkei, J; R. F. A. Zwaal, B. Roelofsen, P. Comfurius, D. Kastelijn \& L. L. M. van Deenen: The asymmetric distribution of phospholipids in the human red cell membrane. A combined study using phospholipases and freezeetch electron microscopy. Biochim. Biophys. Acta 323: 178 193, 1973

22) Balcavage, W. X.; M. Beale, B. Chase \& J. M. Mattoon: Effect of filipin on rat-liver and yeast mitochondria. Biochim. Biophys. Acta 162: 525 532, 1968

23) Cass, A.; A. Finkelstein \& V. Krespi: The ion permeability induced in thin lipid membranes by the polyene antibiotics nystatin and amphotericin B. J. Gen. Physiol. 56: 100 124, 1970

24) Dennis, V. W.; N. W. Stead \& T. E. Andreoli: Molecular aspects of polyene- and sterol dependent pore formation in thin lipid membranes. J. Gen. Physiol 55: 375 400, 1970 